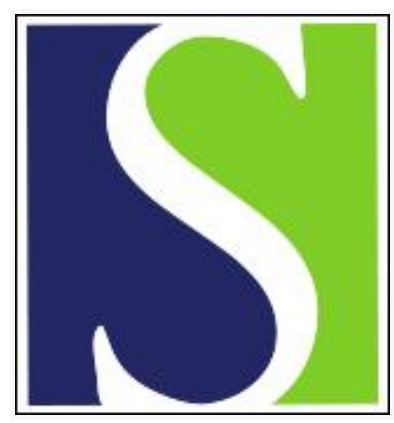

Scand J Work Environ Health 1984;10(5):317-320

https://doi.org/10.5271/sjweh.2323

Issue date: Oct 1984

Skin absorption as a source of error in biological monitoring.

by Aitio A, Pekari K, Jarvisalo J

This article in PubMed: www.ncbi.nlm.nih.gov/pubmed/6523096

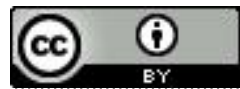




\title{
Skin absorption as a source of error in biological monitoring
}

\author{
by Antero Aitio, MD, Kaija Pekari, MSc, Jorma Järvisalo, MD'
}

\begin{abstract}
AITIO A, PEKARI K, JÄRVISALO J. Skin absorption as a source of error in biological monitoring. Scand J Work Environ Health 10 (1984) 317-320. Concentrations of toluene, tetrachloroethylene, and 1,1,1-trichloroethane were determined in blood collected from both forearms of subjects after one of their hands was soaked for $5 \mathrm{~min}$ in the corresponding solvent or in a thinner containing toluene, as a simulation of the washing of hands with solvent after work. The concentrations of toluene, tetrachloroethylene, and 1,1,1-trichloroethane on the soaked side were high, maximally 5.4, 9.0, and 4.0 $\mu \mathrm{mol} / 1$, respectively, and 20-, 130-, and 35-fold, respectively, compared to the contralateral side. Intraindividual differences were very marked, and dramatic changes were detected within a short period of time. It was not until after $3 \mathrm{~h}$ with toluene and $5 \mathrm{~h}$ with the chlorinated solvents that the difference between the two arms vanished. It is concluded that analyses of solvents in blood specimens drawn during or immediately after the workday may lead to markedly erroneous estimations of exposure.
\end{abstract}

Key terms: organic solvents, tetrachloroethylene, toluene, 1,1,1-trichloroethane.

Absorption of a variety of different organic chemicals through intact skin is well documented $(6,7,10$, $14)$, and it is generally regarded as one of the reasons why one should use biological monitoring of exposure to chemicals. Concentrations of chemicals in the air need not bear any correlation to the amounts absorbed through the skin. However, it is seldom realized that skin absorption may also represent a source of error for biological monitoring (2). The organic chemical concentrations in blood collected from the forearm may not represent those in other parts of the body, but only the local concentrations at the venipuncture site. A prerequisite for this kind of error is that concentrations of the chemical itself - not a metabolite (the majority of which are primarily generated in the liver) - is measured in the blood. In our laboratory, we perform biological monitoring of toluene, tetrachloroethylene, and 1,1,1trichloroethane routinely by analyzing the solvent concentrations of blood and have therefore studied the possible error ensuing from skin absorption.

\section{Subjects, materials and methods}

The studies were performed on two (in case of toluene, three) volunteers. In order to simulate the widely practiced habit of painters who wash their hands after the workday with a solvent, we decided to use a short exposure time of $5 \mathrm{~min}$. We soaked one hand, emerged to the wrist, in a solvent [tetrachlo-

\footnotetext{
1 Department of Industrial Hygiene and Toxicology, Institute of Occupational Health, Helsinki, Finland.

Reprint requests to: Dr A Aitio, Institute of Occupational Health, Haartmaninkatu 1, SF-00290 Helsinki, Finland.
}

roethylene (pa) or 1,1,1-trichloroethane (pa) or toluene (pa) or Dicco ${ }^{\oplus}$ thinner containing $65 \%$ toluene]. In order to minimize exposure by inhalation, the vessel containing the solvent was kept in a fume hood closed with a plastic cover with a small hole for the arm. After the exposure, the hand was washed with soap and water. Blood specimens were drawn through indwelling cannulas (one volunteer, chlorinated solvents) or repeated venipunctures (all other experiments).

Blood was collected in glass vials containing heparin, carefully mixed, and either analyzed immediately (specimens collected during the first $2 \mathrm{~h}$ ) or stored in a refrigerator and analyzed on the following day. Under these conditions of storage no loss of the solvents could be detected.

1,1,1-Trichloroethane and tetrachloroethylene concentrations in the blood were determined with capillary gas chromatography using electron capture detection after hexane extraction, as has been described earlier $(11,12)$; toluene was analyzed with headspace gas chromatography (5) using $o$-xylene as the internal standard.

\section{Results and discussion}

Skin absorption of toluene was studied with the use of pure (pa) toluene and a thinner (Dicco) containing $65 \%$ toluene, $30 \%$ butylacetate, and $5 \%$ butyl alcohol (figure 1). In both cases the difference between the toluene concentrations in the blood drawn from the two arms was marked, the maximal differences being 7-, 13- and 20 -fold for the three persons studied. The highest concentrations of toluene reached were $2.0,2.6$, and $5.4 \mu \mathrm{mol} / \mathrm{l}$. In experi- 

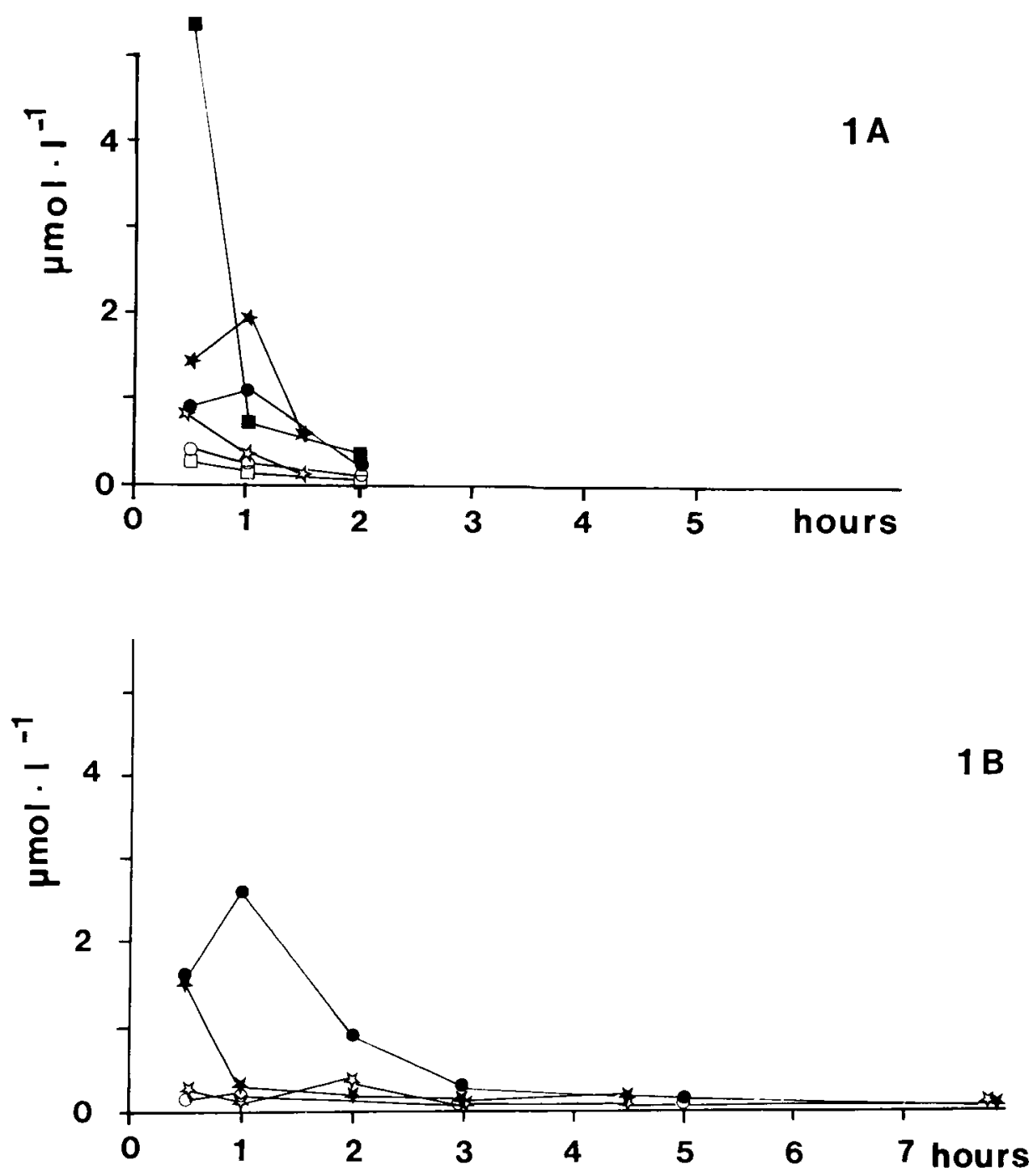

Figure 1. Toluene concentrations in blood drawn from volunteers who exposed one hand to toluene $(A)$ and Dicco ${ }^{\circ}$ thinner containing $65 \%$ toluene (B). (closed symbols: ipsilateral arm, open symbols: contralateral arm)

mental inhalation exposure to $100 \mathrm{ppm}$ of toluene at rest, the concentration of toluene in blood was $4.3-$ $4.9 \mu \mathrm{mol} / 1(1,14)$; during light work a concentration of $14.6 \mu \mathrm{mol} / \mathrm{l}$ was detected (1). In line with the latter finding, a blood concentration of toluene of $12.5 \mu \mathrm{mol} / \mathrm{l}$, may be extrapolated from the data of Apostoli et al (4) for work during exposure to $100 \mathrm{ppm}$; the corresponding value for the figures of Angerer \& Behling (3) is $19.0 \mu \mathrm{mol} / \mathrm{l}$. After $3 \mathrm{~h}$ the difference between the two arms disappeared; thus the practical solution to toluene exposure estimation from blood toluene concentrations is the collection of specimens in the morning before exposure.

The highest blood concentrations of tetrachloroethylene found in blood drawn from the ipsilateral arm after exposure of the hand to the liquid solvent were 9 and $3.5 \mu \mathrm{mol} / 1$ in the two volunteers; those for 1,1,1-trichloroethane were 4.0 and $0.7 \mu \mathrm{mol} / 1$. These values are in line with the findings of Stewart \& Dodd (14) that there is a marked interindividual variation in the skin absorption of 1,1,1-trichloroethane. With these chlorinated solvents the error that skin absorption may cause in the estimation of exposure was even more marked than in the case of toluene; the maximal difference between the arms was 17 - and 130-fold for tetrachloroethylene and 11- and 35-fold for 1,1,1-trichloroethane.

The data on concentrations of chlorinated solvents in blood in inhalation exposure is scanty. Monster (9) reported that continuous exposure $(8 \mathrm{~h} / \mathrm{d}, 5 \mathrm{~d} /$ week $)$ to $50 \mathrm{ppm}$ of 1,1,1-trichloroethane caused a blood concentration (5-15 min after exposure) of $6.7 \mu \mathrm{mol} / \mathrm{l}$, while Savolainen and co-workers (13) detected a concentration of $16.5 \mu \mathrm{mol} / 1$ of $1,1,1$-trichloroethane in 

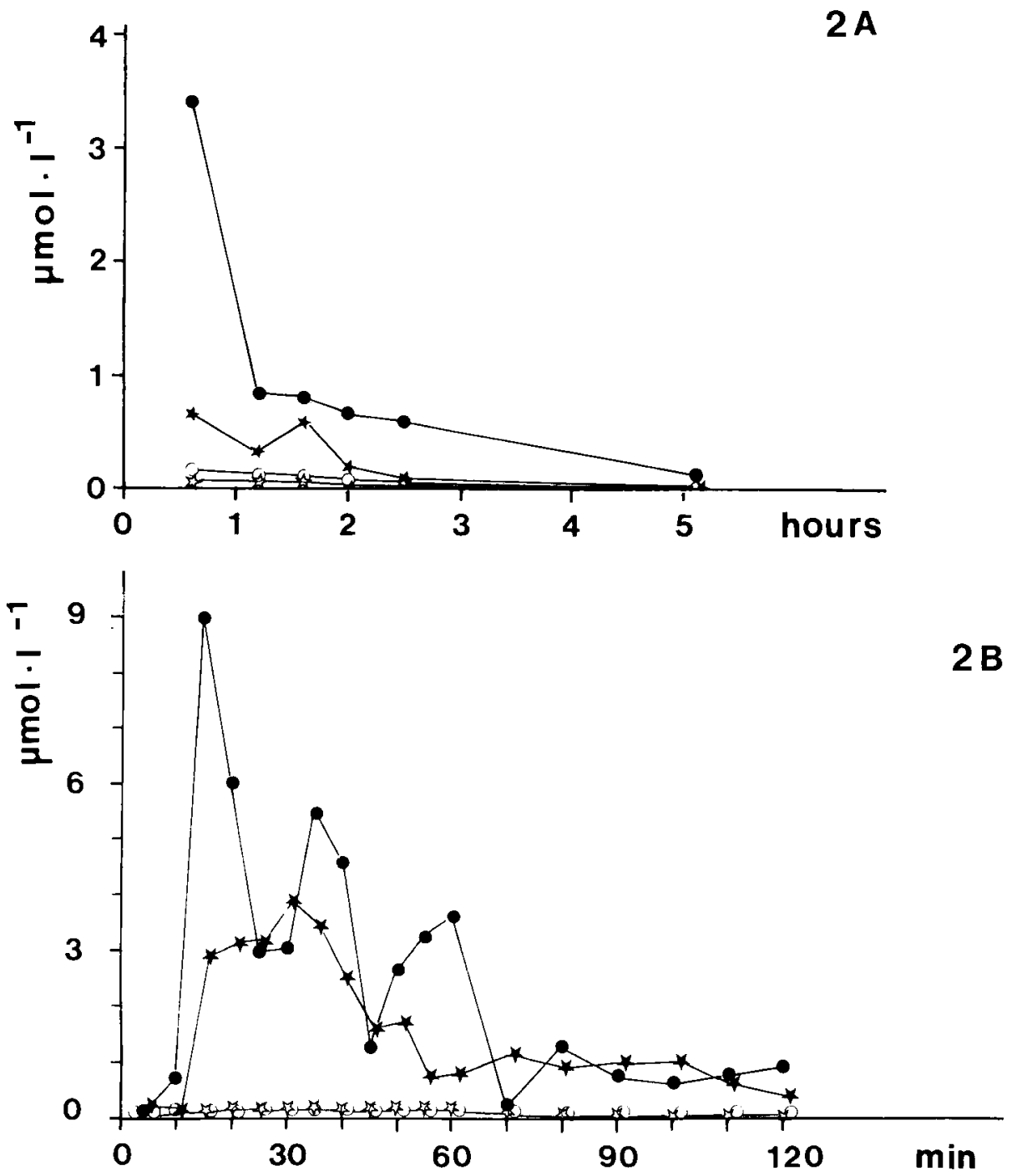

Figure 2. Blood concentrations of 1,1,1-trichloroethane $(\star, \star)$ ) and tetrachloroethylene $(\boldsymbol{O}, O)$ in two volunteers (A \& B) who exposed one hand to the corresponding solvent. (closed symbols: ipsilateral arm, open symbols: contralateral arm)

blood after $4 \mathrm{~h}$ of exposure to $200 \mathrm{ppm}$ at rest. Continuous exposure $(8 \mathrm{~h} / \mathrm{d}, 5 \mathrm{~d} /$ week $)$ to $50 \mathrm{ppm}$ of tetrachloroethylene was calculated to result in a blood concentration of $14 \mu \mathrm{mol} / 15-15 \mathrm{~min}$ after the exposure (8).

The concentrations of chlorinated solvents, especially that of tetrachloroethylene, showed marked fluctuations within a short time interval (figure 2). This phenomenon can probably be explained by physical activity of the arms. Movement causes a flushout of venous blood with a concomitant decrease in the solvent concentration, whereas immobility results in stagnation of venous blood and a build-up of the solvent concentration. These rapid changes add to the uncertainty of exposure estimation. The differences between the chlorinated solvent concentrations in blood from different arms were the most marked im- mediately after the exposure, but they did not vanish until several hours later (figure 2A).

In conclusion, toluene, tetrachloroethylene, and 1,1,1-trichloroethylene, under conditions that probably exist in the workplace, are absorbed through the skin to such an extent that biological monitoring of exposure, based on solvent concentrations in blood specimens drawn during or up to $5 \mathrm{~h}$ after the exposure, may be remarkably erroneous. Correct estimations of exposure may be obtained from specimens drawn in the morning on the day after the exposure.

\section{References}

1. Åstrand I, Ehner-Samuel H, Kilbom Å, Övrum $P$ Toluene exposure: I Concentration in alveolar air and 
blood at rest and during exercise. Work Environ Health 9 (1972) 119-130.

2. Aitio A, Järvisalo J. Collection, processing and storage of specimens for biological monitoring of occupational exposure to chemicals. Pure Appl Chem 56 (1984) $549-566$

3. Angerer J, Behling K. Chronische Lösungsmittelbelastung am Arbeitsplatz IX: Ein Verfahren zur Evaluirung von Grentzwerten für Parameter der inneren Belastung am Beispiel der Toluolexposition. Int Arch Occup Environ Health 48 (1981) 137-146.

4. Apostoli P, Brugnone F, Perbellini L, Cocheo V, Bellomo ML, Silvestri R. Biomonitoring of occupational toluene exposure. Int Arch Occup Environ Health 50 (1982) 153-168.

5. Brugnone F, Perbellini L, Grigolini L, Gazzadori A, Gaffuri F. Alveolar air and blood toluene concentration in rotogravure workers. Int Arch Occup Environ Health 38 (1976) 45-54.

6. Engström K, Husman K, Riihimäki V. Percutaneous absorption of m-xylene in man. Int Arch Occup Environ Health 39 (1977) 181-189.

7. Lauwerys RR. Industrial chemical exposure: Guidelines for biological monitoring. Biomedical Publications, Davis, CA 1983. $150 \mathrm{p}$.

8. Monster AC. Tetrachloroethylene. In: Aitio A, Riihimäki V, Vainio $H$, ed. Biological monitoring and health surveillance of workers exposed to chemicals. Hemisphere Publishing Co, Washington, DC 1984, pp 131139.

9. Monster AC. 1,1,1-Trichloroethane. In: Aitio A, Riihimäki V, Vainio $\mathrm{H}$, ed. Biological monitoring and health surveillance or workers exposed to chemicals. Hemisphere Publishing Co, Washington, DC 1984, pp 141150.

10. Monster AC, Zielhuis RL. Chlorinated hydrocarbon solvents. In: Alessio L, Berlin A, Roi M, Boni M, ed. Human biological monitoring of industrial chemicals series. Commission of the European Communities, Luxembourg 1983, pp 49-104.

11. Pekari K, Aitio A. Determination of 1,1,1-trichloroethane in blood. In: Fishbein L, ed. Halogenated alkanes and alkenes. International Agency for Research on Cancer, Lyon (in press). (IARC manual, volume 8).

12. Pekari K, Aitio A. Determination of tetrachloroethylene in blood. In: Fishbein L, ed. Halogenated alkanes and alkenes. International Agency for Research on Cancer, Lyon (in press). (IARC manual, volume 8).

13. Savolainen K, Riihimäki V, Laine A, Kekoni J. Shortterm exposure of human subjects to m-xylene and 1,1,1-trichloroethane. Int Arch Occup Environ Health 49 (1981) 89-98.

14. Stewart RD, Dodd HC. Absorption of carbon tetrachloride, trichloroethylene, tetrachloroethylene, methylene chloride and 1,1,1-trichloroethane through the human skin. Am Ind Hyg Assoc J 25 (1964) 439-446.

15. Veulemans $H$, Masschelein R. Experimental human exposure to toluene: II Toluene in venous blood during and after exercise. Int Arch Occup Environ Health 42 (1978) 105-117.

Received for publication: 27 September 1984 